\title{
O SÍTIO ARQUEOLÓGICO MENINO JESUS: NOROESTE DO ESTADO DE SÃO PAULO
}

\author{
Paula Cabral de Lima ${ }^{1}$, Neide Barrocá Faccio ${ }^{1}$, Davi Lugli Turtera Pereira ${ }^{2}$ \\ ${ }^{1}$ Universidade Estadual Paulista - UNESP, Departamento de Planejamento, Urbanismo e Ambiente, Programa de pós- \\ graduação em Geografia, Presidente Prudente, SP. ${ }^{2}$ Universidade de São Paulo - USP, Doutorado em Arqueologia, \\ Museu de Arqueologia e Etnologia, SP.E-mail: paulacabral.I@hotmail.com
}

\section{RESUMO}

Neste trabalho apresentamos os resultados dos estudos desenvolvidos para o estudo da paisagem na área do Sítio Arqueológico Menino Jesus, localizado na Bacia do Rio Grande/Turvo, no Município de Orindiúva/ SP. O sítio arqueológico apresentou materiais líticos lascados, líticos polidos e cerâmicos que contribuíram com a identificação e caracterização do possível grupo que o produziu. Para o estudo da paisagem foi utilizado os pressupostos das Ciências da Terra, particularmente a Geomorfologia e a Pedologia, para a interpretação ambiental do contexto arqueológico, com o objetivo de buscar elementos para a compreensão do modo de vida dos grupos que habitaram a região.

Palavras-chave: Sítio Arqueológico, Paisagem, Geomorfologia, Pedologia

\section{THE MENINO JESUS ARCHAEOLOGICAL SITE: NORTHWEST OF THE STATE OF SÃO PAULO}

\begin{abstract}
In this work we present the results of the studies developed for the study of the landscape in the area of the Menino Jesus Archaeological Site, located in the Rio Grande / Turvo Basin, in the conty of Orindiúva, SP. The archaeological site presented chipped stone, polished and ceramic lithic materials that contributed to the identification and characterization of the possible group that produced it. For the study of the landscape was used the assumptions of Earth Sciences, particularly Geomorphology and Pedology, for the environmental interpretation of the archaeological context, with the objective of searching for elements to understand the way of life of the groups that inhabited the region.
\end{abstract}

Keywords: Archaeological Site, Landscape, Geomorphology, Pedology

\section{INTRODUÇÃO}

No trabalho em apreço discorremos sobre o estudo realizado na área do Sítio Arqueológico Menino Jesus, localizado na Bacia do Rio Grande/Turvo. Esse sítio foi estudado pelo enfoque da análise da paisagem, a partir dos pressupostos das Ciências da Terra, particularmente a Geomorfologia e a Pedologia para a interpretação ambiental do contexto arqueológico. Nas Figuras $\mathbf{1}$ e $\mathbf{2}$ apresentamos respectivamente a localização da Bacia dos Rios Grande e Turvo no Estado de São Paulo e a localização do Sítio Menino Jesus. 
Figura 1. Localização da Bacia do Turvo/Grande no Estado de São Paulo

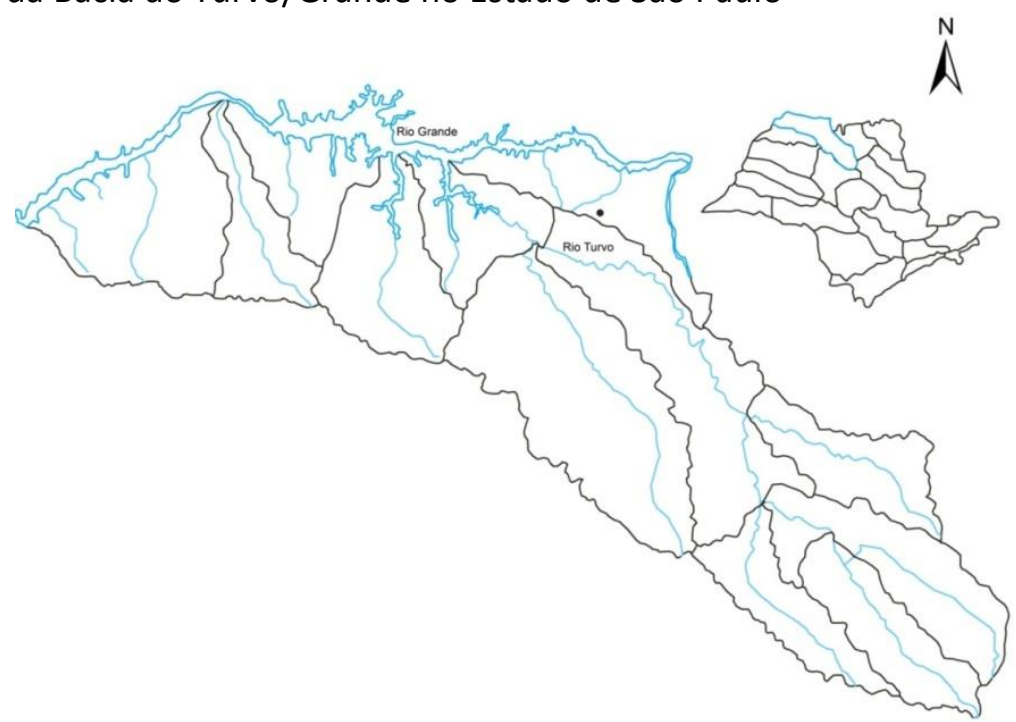

Fonte. Adaptado do Relatório técnico CPTI N. 397/08. Plano de Bacia da Unidade de Gerenciamento de Recursos Hídricos da Bacia do Turvo/Grande (UGRHI 15), 1999.

Figura 2. Localização do Sítio Arqueológico Menino Jesus, no Município de Icém, SP

Fonte de Dados: IBGE, INPE e EMBRAPA, 2010

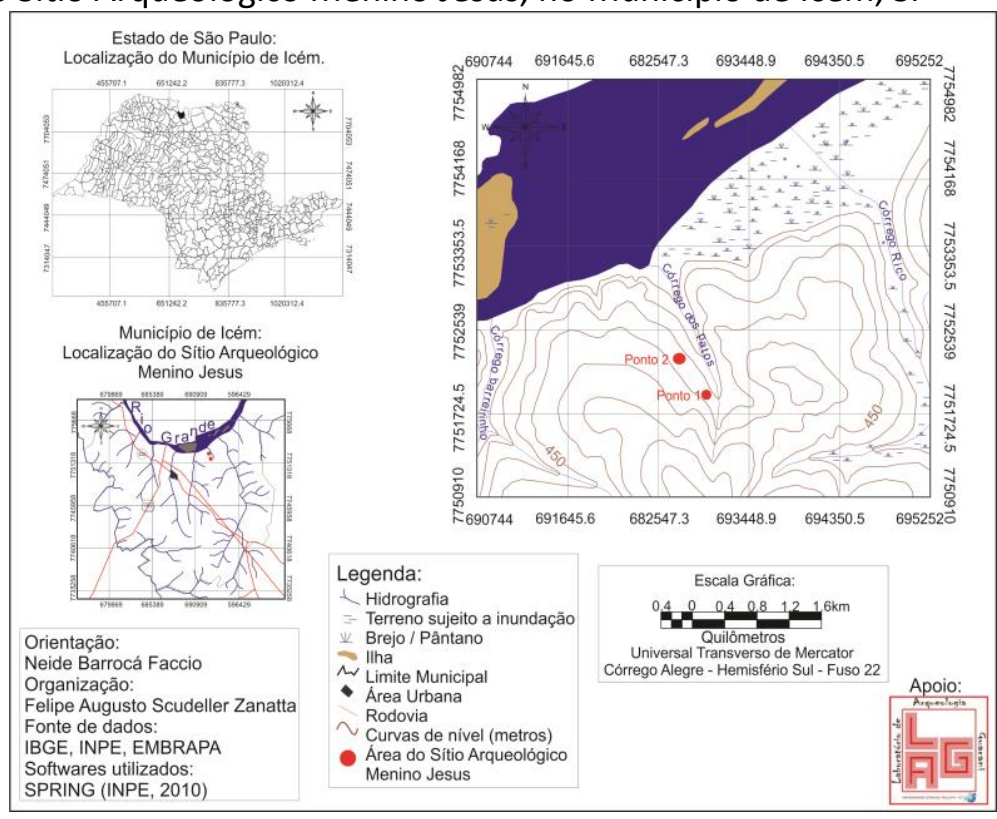

Nesse contexto, foi estudado o Sítio Menino Jesus, localizado em área de licenciamento ambiental, possibilitando a apresentação de novos dados que contribuem para o conhecimento do Sistema Regional de Ocupação do Noroeste do Estado de São Paulo. $O$ sitio como já foi mostrado encontra-se no Município de Icém, SP, na baixa vertente de uma colina ampla as margens do Córrego Menino Jesus, estendendo-se até a margem paulista do Rio Grande.

0 resgate dos materiais encontrados nesse sítio possibilitou a ampliação do conhecimento sobre a Arqueologia Regional. Os estudos realizados até o momento apresentam evidencias de contato entre grupos que produziram a cerâmica da Tradição Aratu/Sapucaí e grupos que produziram a cerâmica da Tradição Tupiguarani. Existe a hipótese de que o Norte do Estado de São Paulo poderia ter sido uma área de interação cultural entre estes dois grupos. Neste sentido, os limites de seu território não eram rígidos e sim fluídos, havendo a possibilidade da ocorrência de um sistema de trocas de bens comuns estimulando o contato sociocultural.

As pesquisas arqueológicas na região Noroeste do Estado de São Paulo são escassas, contudo, a partir de 2003 tiveram um forte impulso com a emissão da Portaria 230 do IPHAN. Essa portaria compatibilizou as fases de obtenção 
de licenças ambientais com os estudos preventivos de Arqueologia. Assim, a partir do ano 2000 muitos sítios arqueológicos foram pesquisados nessa região

\section{METODOLOGIA}

Realizamos pesquisas acerca do meio físico onde foi analisada a Geologia, a Geomorfologia, a Pedologia e a Hidrologia da área do Sítio Menino Jesus. A área apresentou condições para a subsistência dos povos que ali residiram, tendo como fator primordial a proximidade de grandes cursos d'água e fontes de matéria-prima, o que torna o ambiente propício à ocupação.

A paisagem na Arqueologia pode nos trazer informações a respeito da organização sócio espacial do grupo que ocupou o sítio Menino Jesus, tais como: territorialidade, estratégias de acessibilidade aos recursos naturais, redes de troca e interação social, variabilidade da cultura material. 0 meio em que vivemos é um conjunto de fatores que se relacionam e formam o que podemos denominar de paisagem, ou seja, são feições que observamos e que se modificam no tempo e no espaço, sendo essas mudanças influenciadas por diversos elementos físicos, biológicos e sociais.

A Arqueologia da Paisagem é uma abordagem interdisciplinar entre a Geografia e a Arqueologia. Objetiva o estudo das relações dialéticas que se estabelecem entre a sociedade e a natureza, no tempo e no espaço, resultando em uma organização territorial de uma sociedade específica (ARAÚJO, 2001). Na Arqueologia, a paisagem é o espaço concreto visto pelo pesquisador, onde ele concentra seus estudos na busca por entender as consecutivas ocupações humanas, em uma mesma paisagem e as transformações decorrentes da relação sociedade e natureza. É um método de pesquisa onde os artefatos arqueológicos encontrados nos sítios não são a única fonte de informação, pois encontramos também todo um contexto ambiental, utilizando os geoindicadores arqueológicos, que podem fornecer uma série de informações e de evidências sobre as ocupações pré-coloniais.

Geoindicadores arqueológicos são dados do meio físico e biótico que possuem relevância para os sistemas regionais de povoamento e indicam locais de assentamentos antigos. Esses geoindicadores estão presentes na paisagem e são analisados como complementos fundamentais para o entendimento dos artefatos encontrados em sítios arqueológicos (MORAIS, 2000).

Desse modo, as informações extraídas da análise da paisagem são acrescentadas ao estudo da Arqueologia, com vistas a contextualizamos os objetos arqueológicos encontrados, inferindo de um modo cada vez mais preciso sobre como ocorreu o processo de ocupação no Rio Grande/Turvo e a relação dessa população com a paisagem.

A curadoria dos registros do sítio arqueológico Menino Jesus consistiu em levantar informações preliminares sobre as coleções de líticos e de cerâmicas com a finalidade de planejar estudos posteriores ou para sua salvaguarda. A curadoria apresentou informações iniciais, constituindo-se em uma base de dados preliminares.

Inicialmente, realizamos a numeração dos materiais com caneta/nanquim e impermeabilizamos a numeração com verniz incolor, separando os materiais líticos lascados dos materiais polidos e das cerâmicas, após a numeração foi preenchida a ficha de curadoria.

No campo numeração, inserimos a sigla do sítio seguida da numeração do correspondente material analisado. O campo categoria consiste em identificar o objeto em material lítico, cerâmico entre outros. O campo suporte consistiu em identificar o material em instrumento, lasca, resíduo, núcleo, plaqueta, bloco entre outros. O campo matéria-prima consiste em informar qual o tipo de matériaprima. No espaço observações apontamos informação importante sobre o objeto a critério do pesquisador, como por exemplo: "a lasca apresenta fratura na porção distal" ou "cerâmica apresenta entalhe na borda". Por fim, no campo localização inserimos a localização de GPS do material.

\section{RESULTADOS E DISCUSSOES}

A Bacia do Rio Grande/Turvo é composta por 62 municípios, somando mais de um milhão de habitantes em uma área de $16.037 \mathrm{~km}^{2}$. Dentre as atividades econômicas da Bacia existe uma interação entre as atividades agrícolas e industriais, sendo esta uma das características principais do desenvolvimento regional.

As unidades geológicas presentes na área da Bacia Hidrográfica do Grande/Turvo são as rochas ígneas basálticas da Formação Serra Geral (Grupo São Bento), rochas sedimentares 
das Formações Santo Anastácio (Grupo Caiuá) e Vale do Rio do Peixe, Araçatuba, Uberaba, São José do Rio Preto, Presidente Prudente e Marília (Grupo Bauru) e os sedimentos quaternários associados à rede de drenagem (PLANO ESTADUAL DE RECURSOS HÍDRICOS, 2011).

As intervenções arqueológicas ocorreram nos anos de 2013 e 2014, quando foi realizado o monitoramento arqueológico e as etapas de resgate. Na campanha de 2013 foram realizados 18 pontos de coleta na faixa de depleção onde está inserido o sítio. Em 2014, devido à forte estiagem, foi possível percorrer o sítio em sua integridade, sendo possível realizar 349 pontos de coleta de material. Assim, foram totalizados 367 pontos de coleta que apresentaram: 164 peças líticas lascadas, 13 peças líticas polidas e 3130 fragmentos de cerâmica (Figura 3 e Fotos 1 e 2).

Figura 3. Dispersão dos pontos de coleta nas campanhas escavação

Fonte: Pereira (2017)

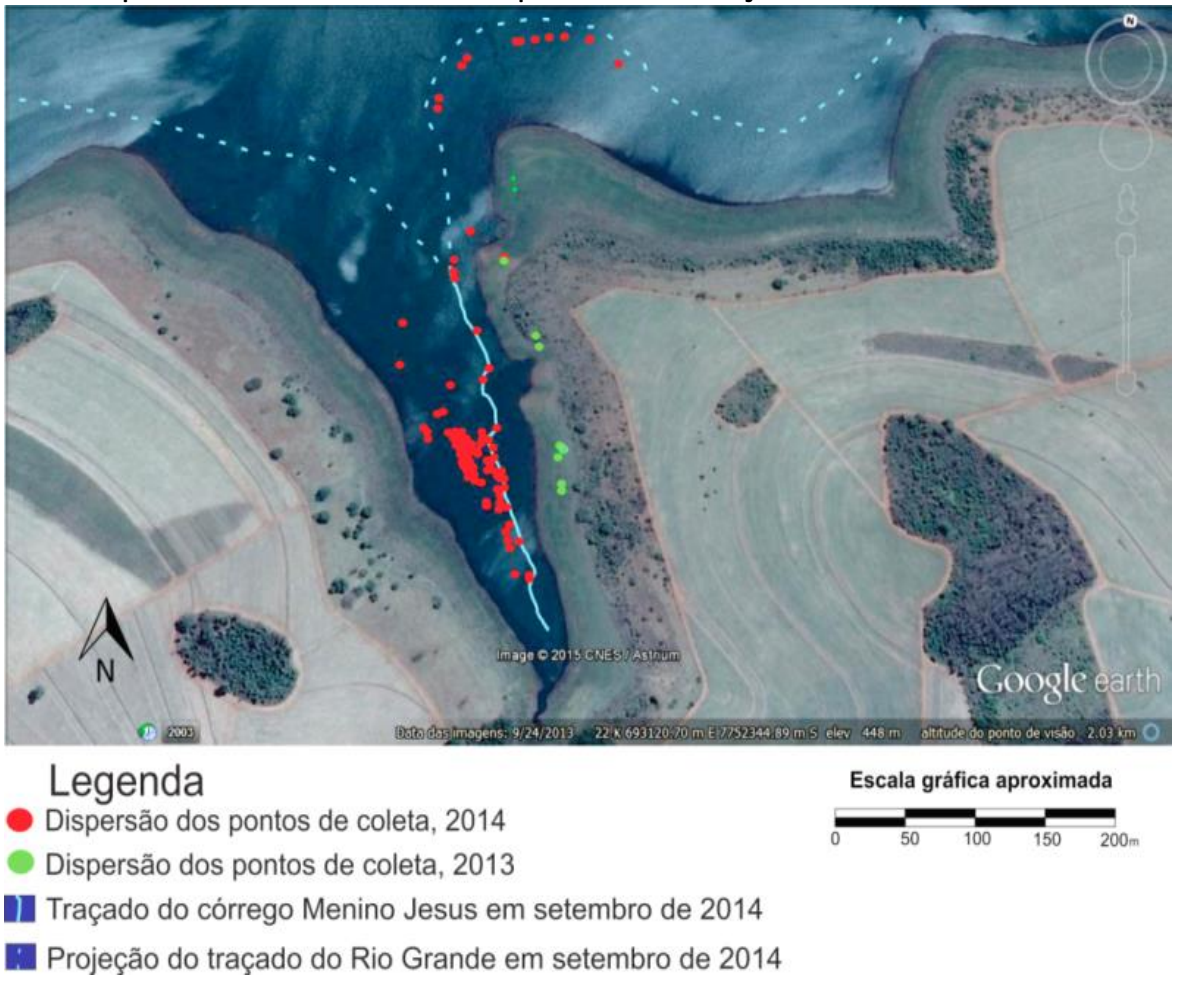

Foto 1 e 2. Exemplares de Matérias primas e Líticos lascados e de matérias cerâmicos encontrados no Sítio Menino Jesus respectivamente
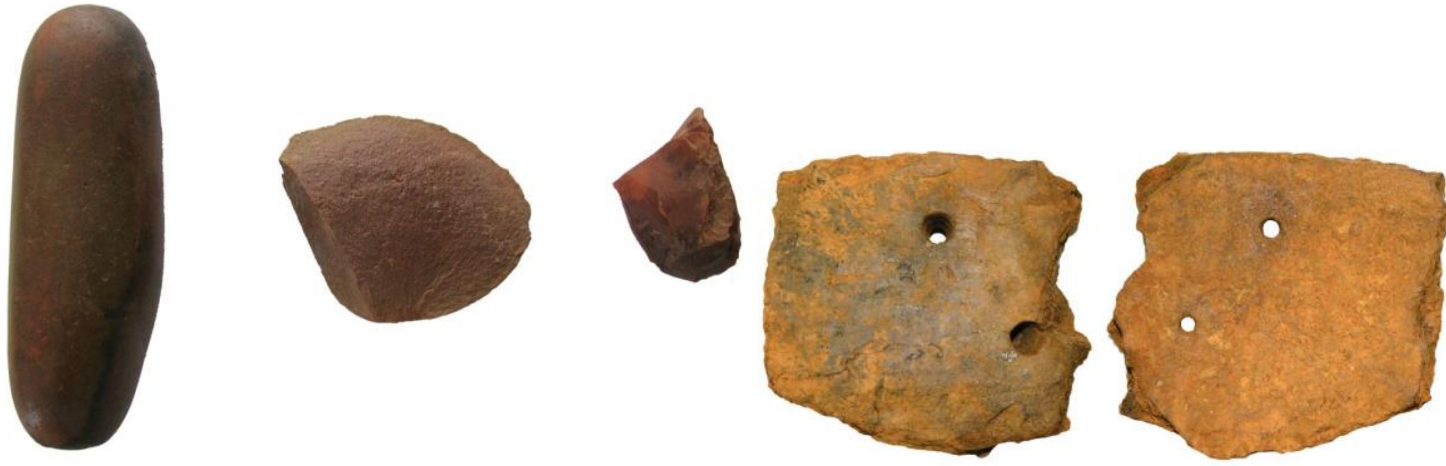

Fonte: Faccio et al.(2010).

De acordo com o Mapa Pedológico do Estado de São Paulo, elaborado por Oliveira (1999), na área em estudo estão presentes três tipos de solos: Latossolos Vermelhos, Argissolos Vermelhos e Gleissolos. O sítio está inserido em área de relevo de degradação, em planaltos dissecados com colinas amplas e colinas médias (OLIVEIRA, 1999).

$O$ relevo de colinas amplas predomina interflúvios com área superior a $4 \mathrm{~km}^{2}$, topos 
extensos e aplainados e vertentes com perfis retilíneos a convexos. Geralmente a drenagem é de baixa densidade e apresenta padrão subdentrítico. Os vales são abertos com presença de planícies aluviais interiores restritas, podendo ocorrer, eventualmente, lagoas perenes ou intermitentes (OLIVEIRA, 1999).

Grande parte da bacia localiza-se no domínio morfoclimático do cerrado cobertos por remanescentes descontínuos de vegetação nativa pertencente aos domínios da Floresta Estacional Semidecídua e do Cerrado, principalmente às zonas de tensão ecológica entre as várias fisionomias vegetacionais a eles relacionadas, como Matas Ciliares, Campos de Várzea, Cerrados e Cerradões. Na Foto 3 é possível ver as duas margens do Córrego Menino Jesus e ao fundo onde aponta a seta encontra-se o Rio Grande.

Fotos 3. Visão Panorámica da area do Sítio Arqueológica Menino Jesus

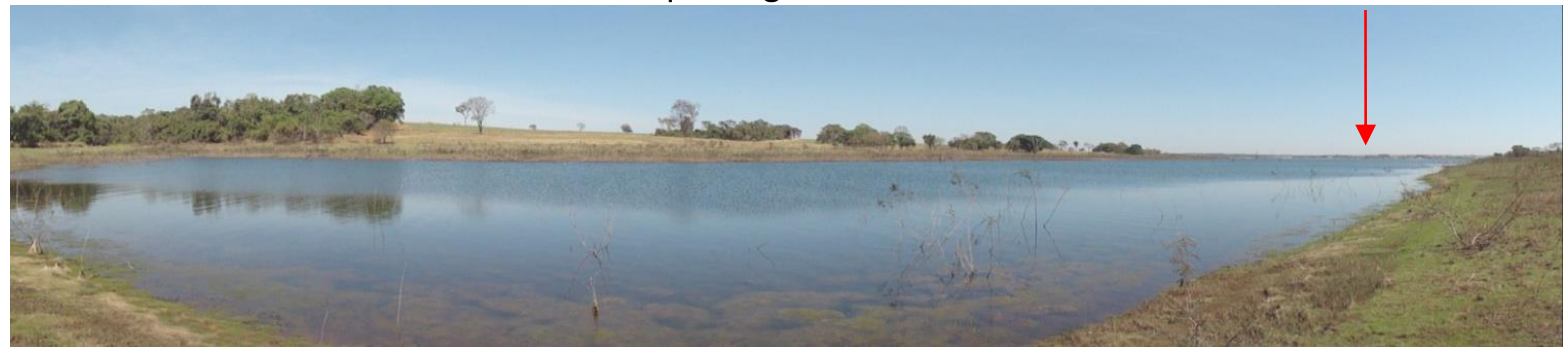

Fonte: Lima (2013).

Para essa análise paleoambiental, interdisciplinar, os vestígios materiais constituem as únicas referências cronológicas dos ambientes sedimentares correspondentes, disponíveis.

O Sítio Menino Jesus foi identificado no ano de 2009, na Margem do Rio Grande, sendo localizados e coletados em seu perímetro fragmentos de cerâmica, líticos polidos e líticos lascados, além de serem evidenciados blocos de basalto com marcas de polimento (Foto 4 ).

Foto 4. Sítio arqueológico Menino Jesus, pesquisadores fazendo o caminhamento para reconhecimento da possível área do sítio.

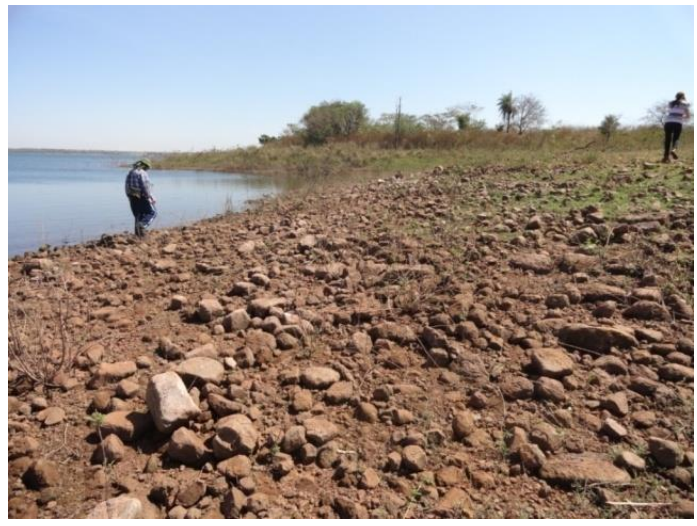

Fonte: Lima (2013).

O Sítio Menino Jesus pode ser considerado como um sítio-habitação. Apresentou configuração linear, sendo identificadas pelo menos duas linhas de deposição arqueológica, em ambas as margens do Córrego Menino Jesus até sua desembocadura com o Rio Grande. O material arqueológico evidenciado e analisado está, predominantemente, associado aos grupos ceramistas Aratu-Sapucaí. No entanto, cerca de $2 \%$ da cerâmica evidenciada no sítio apresentaram engobo branco, vermelho e pintura policrômica em sua superfície, características de grupos ceramistas Tupiguarani.

\section{CONCLUSÃO}

Como pudemos notar a relação homem e meio ambiente possui uma complexidade que perpassa pelas discussões epistemológicas estabelecidas no âmbito de diversas disciplinas. Tem como foco a cultura e o meio ambiente. Estas discussões geraram escolas de pensamento 
com pressupostos teóricos e metodológicos específicos, dentre as quais podemos citar a Geografia, a Arqueologia e dentro destas a Arqueologia da Paisagem.

A respeito da fragmentação dos saberes, pudemos perceber que as ciências estão sempre em diálogo, seja na proposição de técnicas e conceitos ou nos intercâmbios de pressupostos teórico-metodológicos. No âmbito deste emaranhado de ideias e conceitos, análise da paisagem na arqueologia emerge enquanto um viés para a compreensão da relação do homem e natureza no passado. São inúmeras as disciplinas que colaboram na construção da Arqueologia da Paisagem, em especial nas técnicas e ferramentas empregadas na aquisição dos dados, bem como dos referenciais conceituais e teóricos.

\section{REFERÊNCIAS}

ARAÚJO, A. G. M. Teoria e método em arqueologia regional: um estudo de caso no Alto Paranapanema, estado de São Paulo. 2001. Tese (Doutorado em Arqueologia) - FFLCH, USP, São Paulo, 2001.

FACCIO, N. B. et al. Relatório de prospecção sítios arqueológicos turvo/Grande, Relatório de prospecção apresentado ao Iphan em 2010. Presidente Prudente, SP, 2010.

LIMA, P. C. Analise da paisagem na área dos sítios arqueológicos da Bacia do Rio Grande/ Turvo. 2013. Monografia (Graduação em Geografia) - FCT/UNESP, Presidente Prudente, 2013.

MORAIS, J. L. Tópicos de arqueologia da paisagem. Revista do Museu de Arqueologia e Etnologia, São Paulo, n. 10, p. 3-30, 2000. Disponível em: https://doi.org/10.11606/issn.2448-

1750.revmae.2000.109367. Acesso em: 5 de janeiro de 2017

OLIVEIRA, J. B. Solos do estado de São Paulo: descrição das classes registradas no mapa pedológico. Campinas: Instituto Agronômico, 1999.

PEREIRA. D. L. T. Arqueologia da paisagem aplicada ao estudo dos sítios arqueológicos na Bacia do Rio Turvo-Grande, região norte do estado de São Paulo: relatório de qualificação apresentado ao programa de pós graduação em Arqueologia do MAE-USP, São Paulo, 2017.

RELATÓRIO técnico CPTI N. 397/08. Plano de Bacia da Unidade de Gerenciamento de Recursos Hídricos da Bacia do Turvo/Grande (UGRHI 15). Disponível em: http://www.sigrh.sp.gov.br/public/uploads/docu ments/7077/relatorio-final planoturvo grande.pdf. Acesso em: 5 de janeiro de 2017.

Recebido para publicação em 08/08/2017

Revisado em 26/09/2017

Aceito em 02/10/2017 